\title{
DESIGN OF AN AUTOMATED SYSTEM FOR MEASURING CAR BODIES
}

\author{
Piotr Kuryło \\ Institute of Machine Design and Operation, Faculty of Mechanical Engineering, University of Zielona Gora, Szafrana4, \\ 65-516 Zielona Gora, Poland, EU, P.Kurylo@ ibem.uz.zgora.pl \\ Peter Frankovský \\ Department of Applied Mechanics and Mechanical Engineering, Faculty of Mechanical Engineering, Technical \\ University of Kosice, Letná 9, 04200 Košice, Slovakia, EU, peter.frankovsky@tuke.sk
}

\section{Władysław Papacz}

Institute of Machine Design and Operation, Faculty of Mechanical Engineering, University of Zielona Gora, Szafrana4, 65-516 Zielona Gora, Poland, EU, W.Papacz@ibem.uz.zgora.pl

\section{Ingrid Delyová}

Department of Applied Mechanics and Mechanical Engineering, Faculty of Mechanical Engineering, Technical University of Kosice, Letná 9, 04200 Košice, Slovakia, EU, ingrid.delyova@ tuke.sk (corresponding author)

\section{Barbara Schurger}

Department of Applied Mechanics and Mechanical Engineering, Faculty of Mechanical Engineering, Technical University of Kosice, Letná 9, 04200 Košice, Slovakia, EU, barbara.schurger@tuke.sk

Keywords: automation, measurement system, 3D scanners

Abstract: The work presents and describes selected measurement methods of bodywork geometry. The principle of operation of 3D scanners has been described together with their application in the implementation of vision measurement systems in the automotive industry. The paper also presents methods used to automate measurements in diagnostics and vehicle repair processes. In addition, the work presents the concept of a measurement system which combines the ideas of vision measurements and mechanical repair devices.

\section{Introduction}

The current automotive market generates the demand for a fast and efficient technological process to be implemented both in manufacturing and measurement technologies. Product quality verification is desired at every stage of production. It is necessary to quickly respond to changing process parameters to eliminate further processing of defective semi-finished products. The answer to the above requirements is to implement vision measurement and control systems [1].

Vision techniques result from the synergy of optics, photography, electronics, mechanics, control theory, mathematics, and computer science [2]. Together they enable control of the quality of manufactured products from semi-finished products to finished products. Quality control involves obtaining a product image, which is then processed to identify any irregularities or is compared to a reference product. The intensity of production imposes the necessity of using high-speed devices, including effective methods of image analysis [3]. Currently, industrial vision systems are most frequently used to quality control of final products. The global trends show that they are used at every stage of production, inter alia, to supervise and control basic process parameters, which significantly prevents the production of defective products [4].

Vision systems may be classified into four basic application groups [5]:
- $\quad$ vision measurements - to obtain photometric or geometric measurement of products (e.g., to determine the dimensions, position and orientation, order of parts, supervision, etc.),

- vision inspections - in quality control, by photometric or geometric measurement of a given product,

- $\quad$ vision identification - due to the interrelations of objects remaining in the field of the view of a camera, the values of parameters are obtained based on their images,

- machine guidance - obtaining a geometric (full or partial) description of the scene to safely plan and control the movement of the machine (e.g., robot).

In quality control systems, a non-contact control of the product parameters is frequently required (e.g., geometry, roughness, shape errors, etc.). Often, due to harmful working conditions or difficult availability of the inspection location, machine is the only solution. Vision systems also allow the generation of reports enabling the assessment of the quality of significant technological processes in the product production processes. They are particularly useful in production based on certified quality management systems [6-8]. The above-mentioned properties contribute to the increasing popularity of automated vision systems for quality control [9-11]. With the proliferation of computer technologies, including matrix image converters, vision systems have been successfully used in the automotive industry. Automation of the process of bodywork measuring with the use of 
DESIGN OF AN AUTOMATED SYSTEM FOR MEASURING CAR BODIES

Piotr Kuryło; Peter Frankovský; Władysław Papacz; Ingrid Delyová; Barbara Schurger

cameras and 3D scanning technologies significantly shortens the process of vehicle production, and thus translating into increased production efficiency. A modern, visual method of measurement has supplanted previously used technologies based on analogue devices.

New methods and measurement concepts are currently being developed and implemented, an example of which is a reverse engineering technology or coordinate measuring technology. Reverse engineering relies on digitizing the geometry of a real object. The result of this process is the digital form of the model, which constitutes the basis for further technological and constructional works as well as analyses. A coordinate measuring technique is characterized by measurement procedures based on coordinate values of measuring points. It enables the determination, with a relatively high accuracy, of dimensions of spatially shaped machine parts. Implementation tools for both processes are 3D scanners and measurement systems created with their use $[8,12,13,15]$. Two basic groups of scanners are distinguished: non-contact scanners and contact scanners [12-14]. The division of existing scanners is shown in Figure 1.

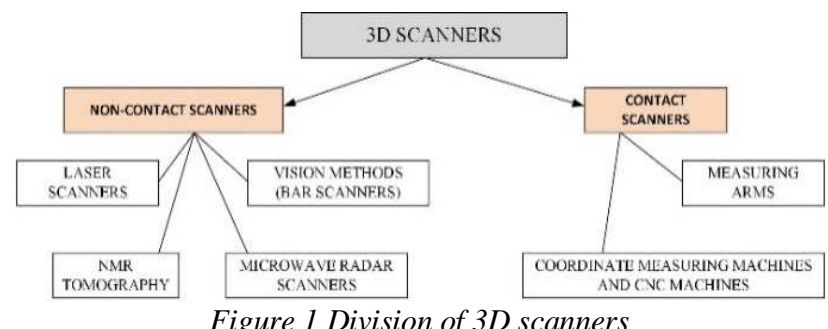

The aim of this study is to indicate possible utilization of vision systems in the repair processes of self-supporting load-bearing structures of vehicles. The modern vision systems were analysed and a concept of a structure of a system for measuring the geometry of bodywork for the needs of vehicle construction and repairs was developed.

\section{The use of selected vision systems in bodywork designing}

The shape of the bodywork significantly affects not only the aesthetics of the vehicle itself, but above all, its technical parameters. It includes all safety issues and questions related to the quality assurance system [16]. The external appearance of a vehicle is affected by the surface and the spatial form of the bodywork. Smoothness (streamlines) of the surface and lines dividing the bodywork into individual elements determine not only aesthetic values, but also affect aerodynamic properties. In the process of constructing the bodywork, there is a need to create specific surfaces and then to dimension them accurately. Currently, there are two methods of constructing vehicle bodywork: a traditional method and an (intensively developing) computer method. The first method involves developing a physical bodywork model, and then the construction documentation is prepared. The second method is based entirely on the building of virtual 3D models [17].

Three main factors are taken into account in the design of self-supporting bodywork:

- manufacturing costs,

- functionality,

- $\quad$ unladen mass of the bodywork, which determines the resistances of vehicle movement and directly affects the fuel consumption.

Automation of a construction process is primarily the introduction of computer technology to every stage of design. The basis for elaboration of a computerized documentation is a precise digital image of the surface performed with the use of one of the CAD systems. The quality of the developed structure can be checked without referring to a real model. Thanks to this, it is possible to correctly create original and sophisticated shapes. In particular, the digital recording of the surface, obtained thanks to the digitalization of the reduction models, eliminated the long-lasting and costly stage of mastermodel construction $[18,19]$.

$3 \mathrm{D}$ scanning employed in the process allows quick and accurate formation of three-dimensional documentation of physical objects. The result of the scan is a complete digital model, which can later be edited and processed by CAD/CAM programs as well as prototyping, visualization and animation programs. Thanks to the digitalization of reduction models with the use of scanners emitting structural light, the whole cycle of bodywork formation is significantly shortened. This is due to the shortening of the surface shaping time, the rapid digital recording of its parameters, the ease of assessing the quality of the developed surface and the ease of introducing any corrections or modifications. The time needed for the preparation of drawing documentation is also significantly limited. The documentation is now acquiring a secondary importance since a digital record of the surface forms the basis for the next stages of work. Based on this record, calculations of elements strength (MES) may be performed, and programs for numerically controlled machine tools or pressing tools (both of which may be used in production of a final model) may be developed. After the "electronic" assembly of individual elements, construction nodes or the whole bodywork, it is possible to test the bodywork in terms of safety, aerodynamics, or acoustics with the use of computer simulations. Thus, the so-called virtual model is formed [19-25].

One of the systems supporting the digitization process is the Bruckmann's NaviSCAN3D scanning system. The main feature of this system is the use of a set of cameras that track the position of the scanner in the measuring space and the use of a spatial reference frame (as an element of the scanner head). The solution works well in the case of measurements of large elements, eliminating the process of preparing the measured element before the measurement 


\section{DESIGN OF AN AUTOMATED SYSTEM FOR MEASURING CAR BODIES}

Piotr Kuryło; Peter Frankovský; Władysław Papacz; Ingrid Delyová; Barbara Schurger

(applying reference points and using the photogeometry system). The system allows full automation of the digitization and measurement process. Properly configured measuring system [26-29] enables:

- $\quad$ scanning of aluminium and galvanized steel elements without applying antireflection coatings. The scanning system collects accurate data from highly reflective areas,

- $\quad$ scanning with high accuracy of both the surface of the element and the edge of the holes, leaving the cutting lines,

- application of a robot: the limited absolute positioning accuracy of the robot has been compensated by a large volume tracking system, and verification of each scanner position while setting the process parameters. Such defined positions of individual views were the basis for the next measurement series,

- the process time significantly shortened.

Figure 2 - Figure 4 present the formation of digital documentation and the archiving process on the example of a vehicle door prototype. Figure 2 shows the NaviSCAN 3D scanner installed on the KUKA industrial robot [29].

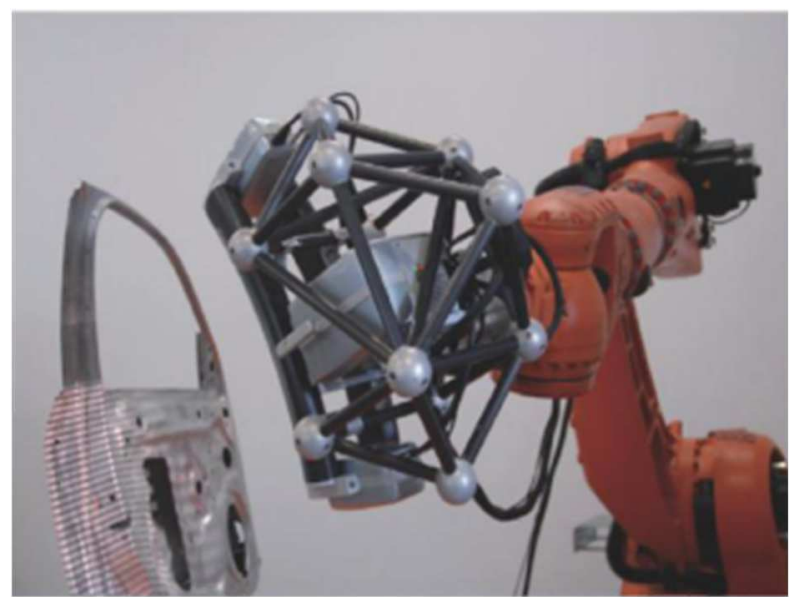

Figure 2 The process of digitization of an element with a bar scanner

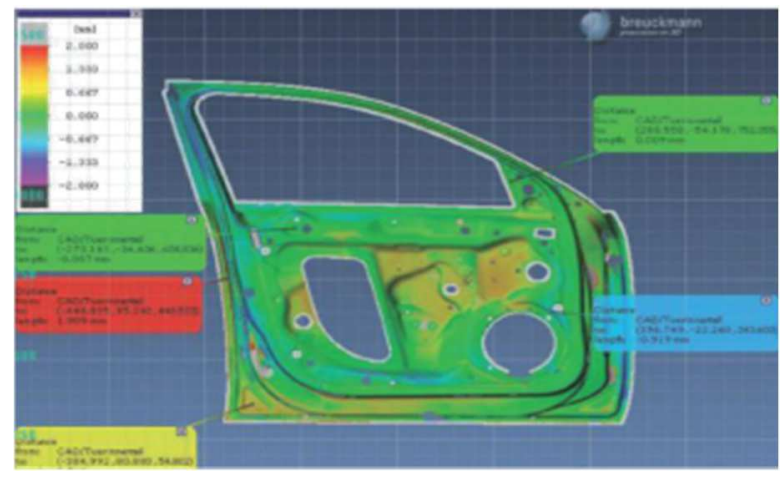

Figure 3 Image generated by the system. A map of deviations SCAN vs. CAD

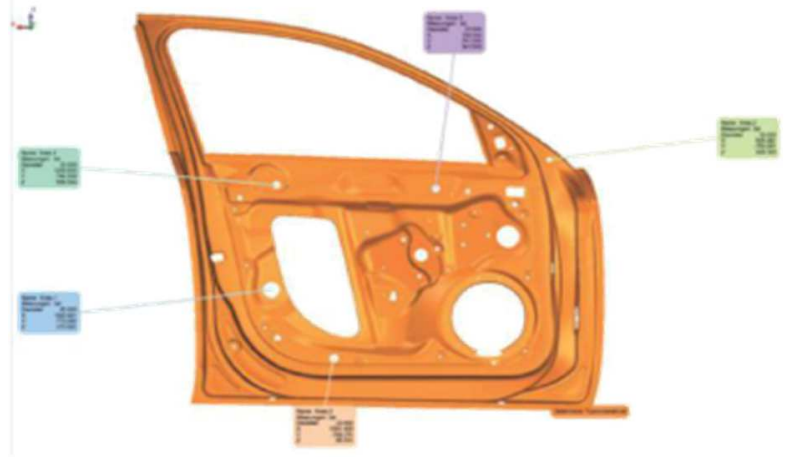

Figure 4 Verification of the coordinates of the position of the centres of selected holes

Digital documentation and archiving of prototype elements of bodywork allow for [30]:

- fast and precise 3D data generation by the NaviSCAN3D system,

- full digitization of an element in a few minutes, the average scanning time is about 15 minutes,

- full automation of the measurement process human intervention needed only to fix the measured element on the table,

- automatic generation of measurement reports thanks to the use of advanced tools for data inspection (Rapidform, Polyworks).

The measuring systems using scanners that emit structural light outside the measurement are ideal for product quality control processes thanks to the fact that they allow quick comparison of the manufactured element with the project, which, in turn, enables detection of manufacturing errors, comparison of cross-sections, or else the identification of areas exceeding the assumed tolerance [31-35]. Digitization and quality control improve the product development and optimization processes and the production preparation.

The current bodyworks created regarding safety requirements are supplied with energy-intensive zones, which are subject to strong deformation during a collision. Bodywork repairs of this type are more complex. They can be divided into two categories:

- the first, which includes the replacement of permanent elements of the bodywork structure,

- the other, consisting of straightening the structure and replacing the damaged parts or entire welding assemblies forming the bodywork [36].

The first type of bodywork repairs consists in replacing external equipment elements, external coating or covers and local bodywork repairs which restore the original shape of the element.

The second type includes the repair of medium and serious damage to the bodywork supporting structure. Repairing such damaged bodywork requires replacing some elements of the structure or even whole welding assemblies and restoration of the proper bodywork 
DESIGN OF AN AUTOMATED SYSTEM FOR MEASURING CAR BODIES

Piotr Kuryło; Peter Frankovský; Władysław Papacz; Ingrid Delyová; Barbara Schurger

geometry. The geometry of the body is connected with the correct mutual position of many characteristic points related to fastening of mechanical assemblies such as the vehicle suspension, travel gear and drive system. Improper geometry of the bodywork directly affects the safety of the vehicle [37-39].

The latest equipment solutions include the proper repair and measurement systems equipped with a computer and electronic sensors. Important features of the system include the simple service and their versatility enabling the repair of bodyworks of various makes and types [40].

The diagnosis, measurement and repair of bodywork should include [41,42]:

- $\quad$ setting and fixing the bodywork to the frame,

- levelling the bodywork on the frame,

- $\quad$ finding a few characteristic points (minimum $3 \div 4$ ) that were not displaced during the collision,

- replacement of damaged elements and systems,

- disassembly of external coating and covers,

- $\quad$ stretching (straightening out) damaged elements of the bodywork and bringing them to such a form that the remaining control points were in the correct places, according to documentation provided by the vehicle manufacturer,

- $\quad$ checking the position of all characteristic fixing points of mechanical components (fixing them to the bodywork),

- $\quad$ replacement of damaged elements and systems (with the new ones),

- assembly of the external coatings and covers.

A list of control dimensions characteristic for a given body (measuring points) is included in the company's repair manual or specialist literature. Some of these dimensions refer to fastening mechanical assemblies while others determine the geometry of the bodywork associated with the assembly of windows, covers and other elements.

\section{Selected modern measuring and repair systems for vehicle bodywork}

Mechanical measuring devices usually have a modular construction [43]. Figure 5. presents such a device made by Autorobot, a Finnish company [44].

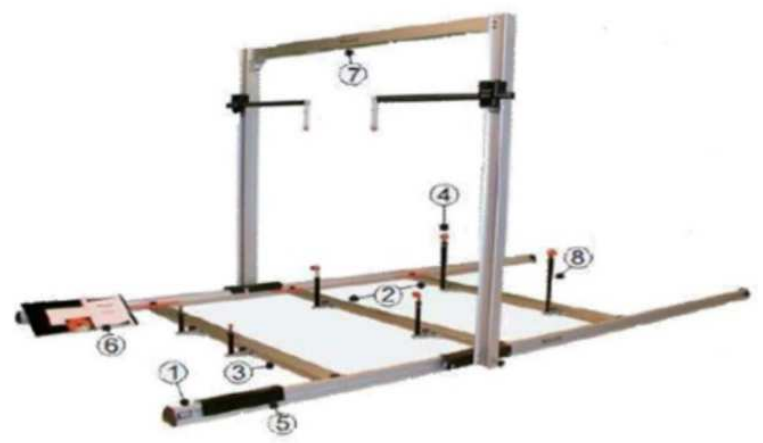

Figure 5 Mechanical device made by Autorobot, used in bodywork repairs. 1 -longitudinal beams, 2 - symmetrical measuring bridge, 3 - independent measuring bridge, 4 measuring heads, 5 -protectors, 7 -movable gate, 8 -boom

The basic element of the device is a movable gate (7) placed on the lower longitudinal beams (1). The gate may move along the beams to the points which are to be measured. The construction of the Autorobot mechanical measuring device includes symmetrical measuring bridges connecting longitudinal beams. The special booms, with measuring heads on them, are attached to the movable gate and to the measuring bridges. The internal space of the device is $1890 \mathrm{~mm}$ high and $2070 \mathrm{~mm}$ wide. The length of the booms is adjustable from $0.5 \div 4$ meters. Measurement with a mechanical measuring device consists in reading three coordinates of the measured point i.e., the coordinate of height, width and length. The Autorobot measuring system is equipped with data files (on disk or on the Internet) containing information about the location of measurement points for various vehicle brands. This allows the use of the measuring system during repair work with the possibility of evaluating deviations from the factory data [44].

Figure 6 shows sample measurement cards [44]. Thanks to the large database, it is possible to measure all chassis structures including assembly points, McPerson columns, suspension frame, etc.

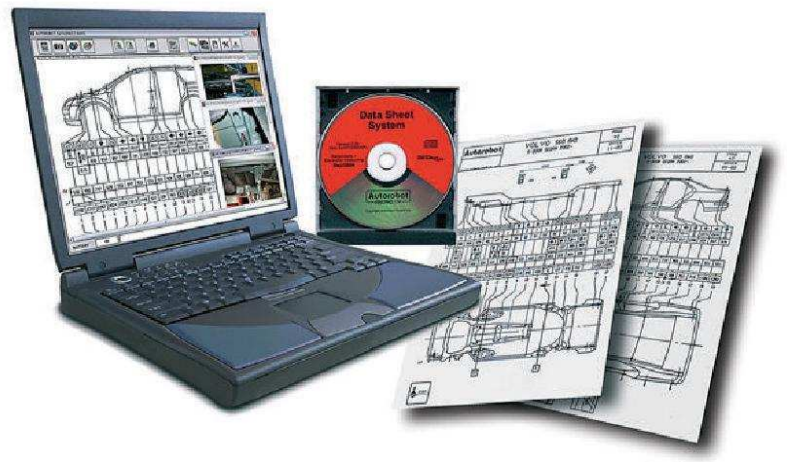

Figure 6 Examples of measuring cards (in paper form and on CDs) containing base points

The Autorobot system is equipped with measuring data for the bodywork and chassis of 2000 types of car brands. The data is updated and supplemented every quarter. A mechanical measuring device can be used both to control the straightening process and to check the results of repairs.

The Swedish company Car-O-Liner offers electronic measuring devices: Car-O-Tronic Classic, Vision and Vision X3. The Car-O-Tronic Classic is a computer measuring system that supports the entire repair process from damage analysis to after repair checks and the formation of the repair documentation. This system allows the measurement of all base points of the bodywork and chassis using a simple jack, a channel or directly on the floor. The discussed Car-O-Tronic Classic device is shown 


\section{DESIGN OF AN AUTOMATED SYSTEM FOR MEASURING CAR BODIES}

Piotr Kuryło; Peter Frankovský; Władysław Papacz; Ingrid Delyová; Barbara Schurger

in Figure 7 (during measurements of a car being repaired) [45].

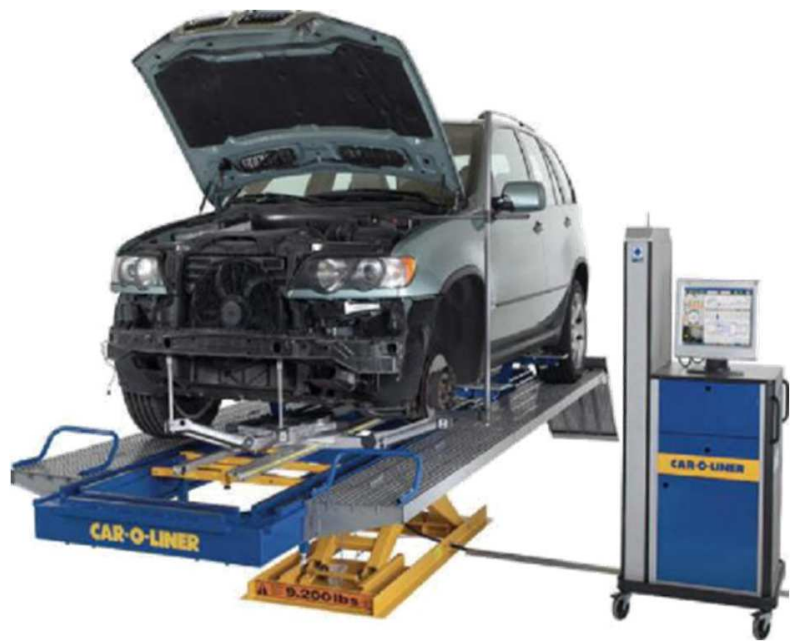

Figure 7 Electronic Car-O-Tronic Classic measuring system during bodywork repair

The measuring system consists of a measuring bridge that acts as a carrier for the rest of the system's measuring elements. The measuring bridge is equipped with guides with measuring rulers with attached micromarkers. They are all mounted on a frame fixed on a scissor lift. The module with the measuring head, which is used to read the position of the measuring points, moves along the measuring bridge. The module is shown in Figure 8 $[46,47]$.

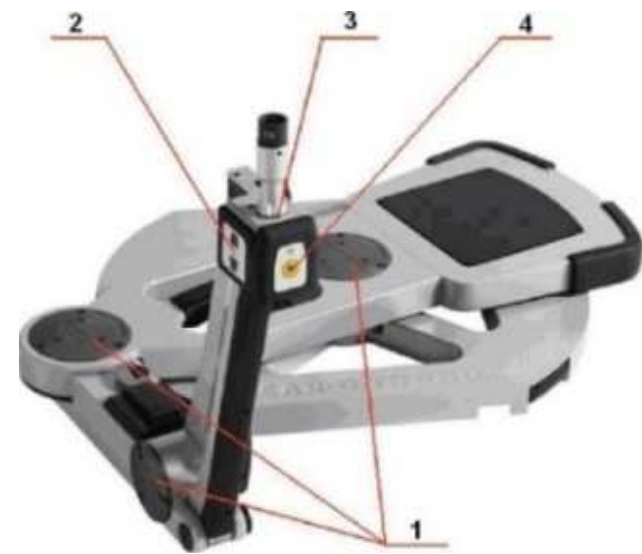

Figure 8 Car-O-Tronic measuring head, where: the measuring module consists of three rotary joints marked as: 1 -joints providing information in a continuous cycle. The positions are read three times per minute, 2 - the communication system (included in module 2) with a central unit is wireless. The exchange of measuring tips of various lengths, angular settings and diameters is carried out using a quick connector, 3 - the module is equipped with a socket (4) for connecting external devices.

A replaceable measuring tip is attached to the measuring head. The system also includes a data sheet (base points) and software enabling real-time tracking of the tip's movement relative to the point given in the database. Data from the head is sent wirelessly to the central unit. The position of the measuring tip relative to the position required for a given vehicle type (when measuring characteristic points) can be observed on the monitor screen (Figure 9) [49].

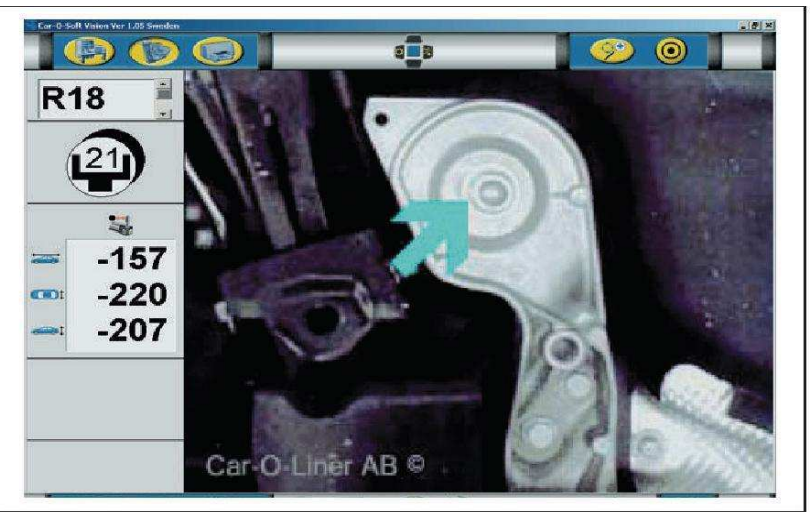

Figure 9 Screen with a visible measuring point position.

In the most advanced version, the device is equipped with automatic centring systems and a base of photographs of elements with marked measuring points for each of the available car models. The so-called measurement cards (Figure 10) are developed in cooperation with car manufacturers (over 15500 measuring cards of car models in the database) [47]. Data update is performed quarterly. With the help of an electronic system, repair documentation can be issued (prints in graphical form or containing magnitude values, before and after repair).

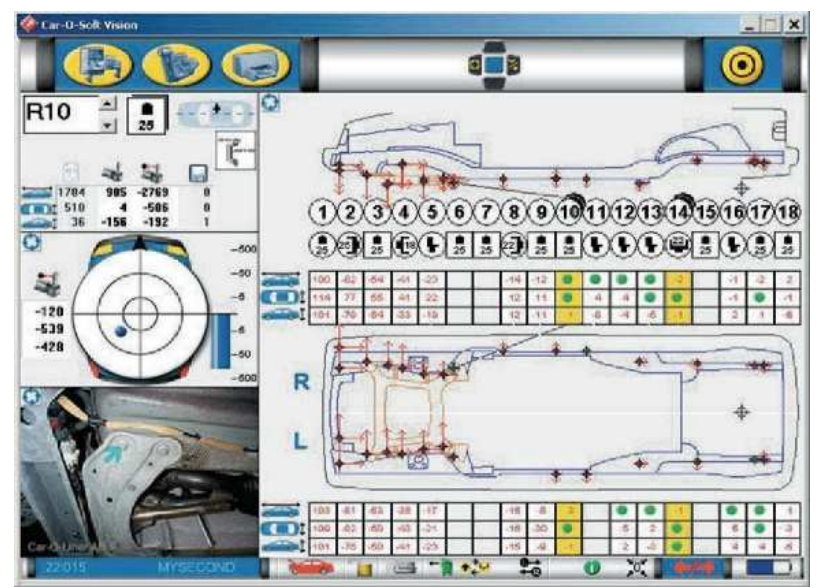

Figure 10 Screen with a visible measuring point position measurement card and base points

\section{The concept of a visual measuring system supporting vehicle bodywork repairs}

The basic assumption of the conducted research was to perform a detailed analysis of the possibility of connecting a repair frame with a vision system enabling full 
DESIGN OF AN AUTOMATED SYSTEM FOR MEASURING CAR BODIES

Piotr Kuryło; Peter Frankovský; Władysław Papacz; Ingrid Delyová; Barbara Schurger

dimensional control in real time of the process of straightening of damaged elements of bodywork. An attempt was also made to develop algorithms for elements straightening, considering the strength parameters of the materials used in their production [49].

The system was built using the RN-4300 Standard repair frame manufactured by Zakład Mechaniki Maszyn from Trzcianka near Piła (Figure 11). The frame is intended for repairs of self-supporting bodyworks of passenger cars and delivery vans. It is featured by high stiffness and has well thought solutions for fixing additional equipment. It is well equipped and good value for money [49].

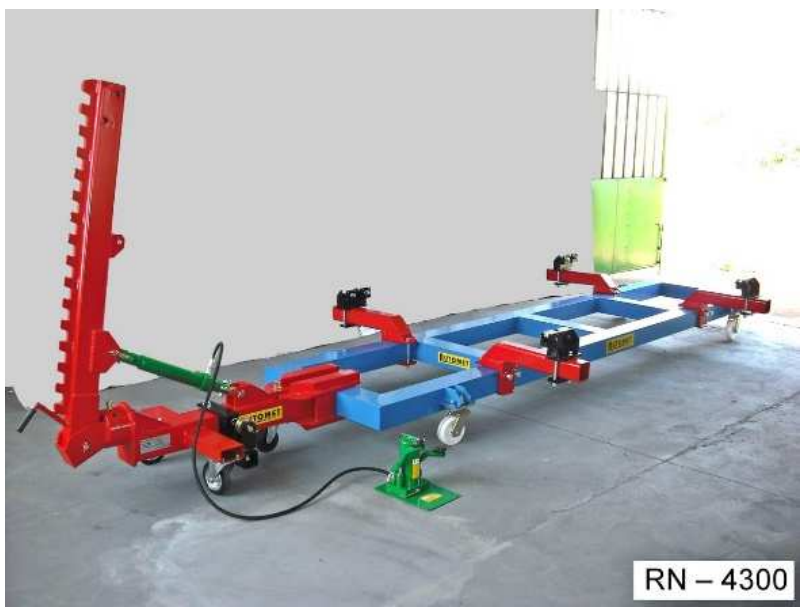

Figure 11 Repair frame RN Standard

The frame consists of the following elements and features the following technical parameters:

- the frame skeleton is $5500 \mathrm{~mm}$ long and $6100 \mathrm{~mm}$ wide,

- $\quad$ sliding side arms to attach the jaws,

- hydraulic straightening unit,

- jaws for fixing the bodywork to the frame,

- $\quad$ special attachments for fixing vans and buses.

The frame has an Xpectia FZ3 vision system from OMRON featuring:

1. depending on the model, it is possible to connect from 1 to 4 cameras with a CameraLink-camera interface (with a resolution from $300 \mathrm{k} \div 5 \mathrm{M}$ pixels),

2. it is possible to integrate the illuminator with the camera and video system,

3. Data transmission takes place via the RS232C / 422A serial port or the 100BASE-TX / 10BASE-T network interface,

4. it is equipped with 11 analogue inputs and 26 digital outputs,

5. has 4 USB $1.1 / 2.0$ ports for pointing and storing devices,

6. 32 groups of scenes, each group contains 32 scenes.
The structure of the Xpectia FZ3 system is shown in Figure 12.

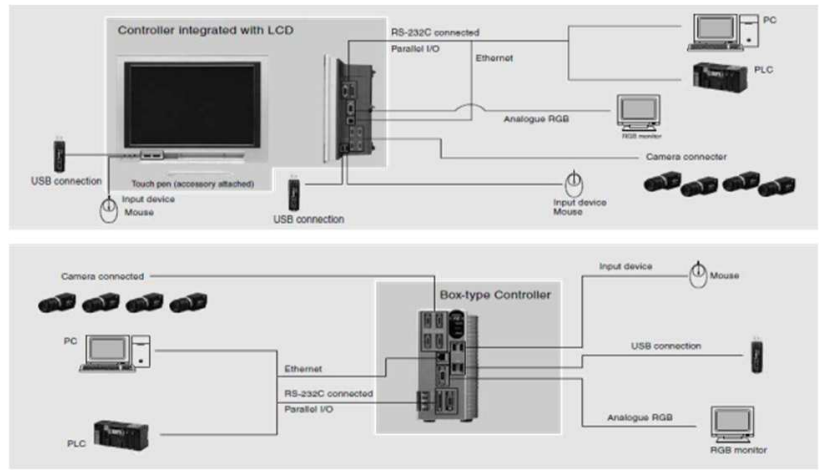

Figure 12 Xpectia FZ3 system configuration

All devices of the vision system were connected to the controller integrated with the touch panel or the box-type controller. Flash memory was used to store more data and measurement settings. For communication with other devices, the Xpectia FZ controllers used the LAN (Ethernet) interface and the parallel port. Measurement data is made available through the embedded FTP server. Xpectia FZ3 devices are equipped with a powerful processor that enables the operation of cameras with a resolution of up to $5 \mathrm{Mpx}$. The methods of initial data processing (preprocessing) and measurement methods have been introduced. There is a possibility of removing a repeating background pattern from the image. It is also possible to repeatedly search a given pattern on the observed scene, to eliminate trapezoidal distortions or to combine images from several cameras. Integration of images from several cameras into one allows obtaining a larger measurement field. Together with a vision measurement system, the manufacturer provides software that enables relatively simple, intuitive operation.

Before starting the repair process, it is very important to carry out a properly planned calibration of the measurement system.

The calibration of the vision system was based on the Single camera (monovision) method e.g., using the Matlab Camera Calibration Toolbox for Matlab, which allows measuring the distance between three points (three points corresponding to the technique of measuring the position of three characteristic points on a selected surface).

To obtain information about the location of the measurement points, it was first necessary to determine the coordinates $(\mathrm{x}, \mathrm{y})$ of the space and then to obtain information on the location of these points in this space. This involved the use of 20 images (sequence of 20 photos from the camera equipped with the CameraLink interface). It was important that all measuring points were in one image.

Figure 13 shows points: P1, P2, P3 representing three measuring points that map the distances between these points in a two-dimensional space. In the canonical system, 
the corresponding points in the image plane of the camera are connected by the so-called epipolar lines.

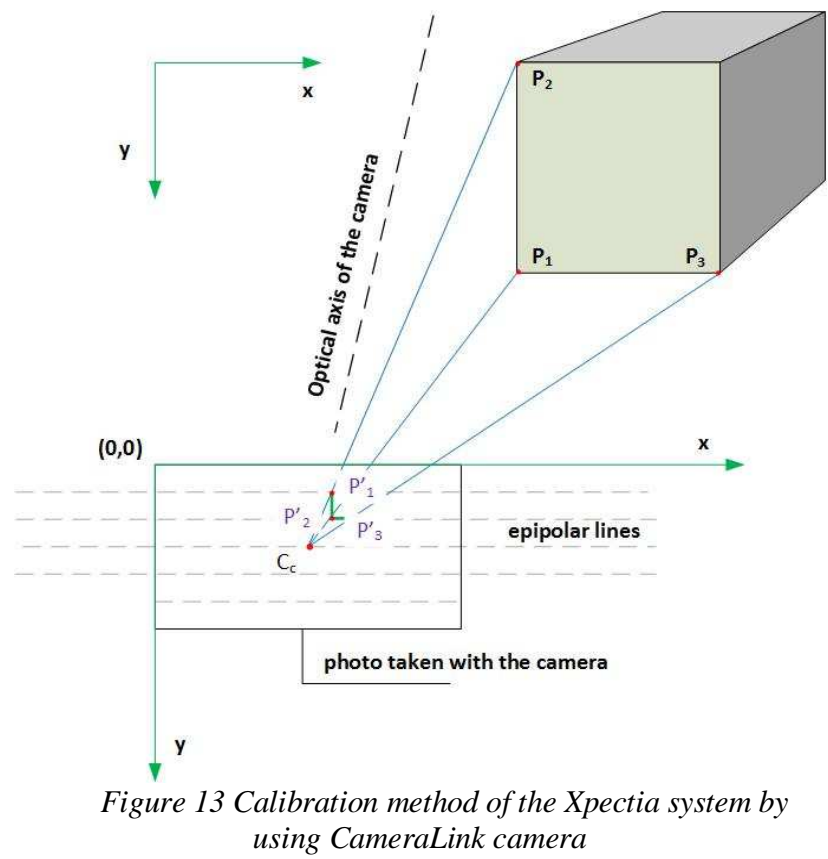

Based on the sequence of 20 corresponding photographs taken in the monovision technique, the calibration procedure should first be carried out i.e., the verification of the distance between the measuring points using the Camera Calibration Toolbox in the Matlab package. The average image reprojection error was 0.8 pixels per photo.

Subsequent stages of working with the Xpectia system:

- $\quad$ programming the Xpectia system - preparing a scene (scenes) containing a sequence of function blocks performing selected tasks, the first block of the scene downloading the image,

- the successive blocks are associated with the processing and recognition of the content, image and the implementation of other tasks,

- $\quad$ each block returns the overall result in the form of $\mathrm{OK} / \mathrm{NG}$ (correct/incorrect) and individual detailed information specific to it,

- $\quad$ at the end of the scene sequence, the information available from individual blocks can be used to make the final decision and the appropriate response, the information obtained can be displayed in the image preview area and sent to other devices via available interfaces.

Figure 14 shows a diagram of the proposed connection between the repair frame and the vision system.

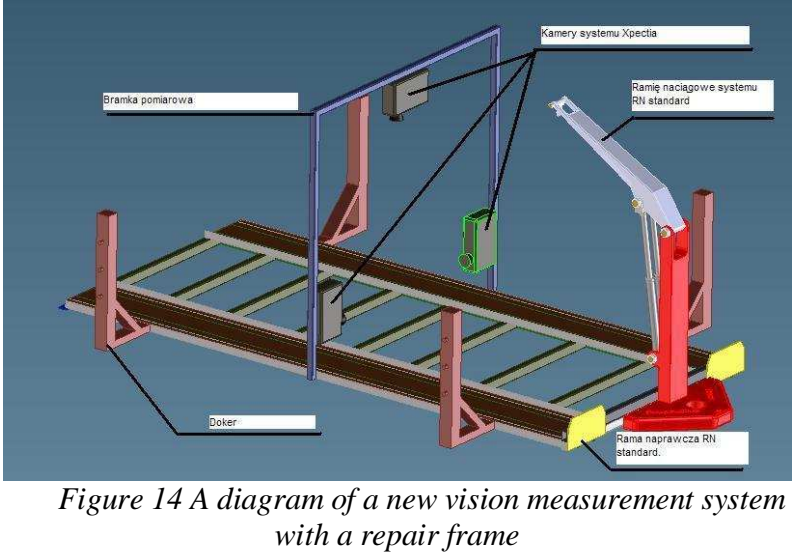

The measuring gate has been integrated with the repair frame. There are 3 cameras of the Xpectia system on the gate. They allow the measurement of the geometry of bodywork and chassis during repair work in real-time.

The basic components of the appliance are as follows:

- repair frame with a stretching arm,

- measuring gate with a vision system mounted,

- measuring-control software.

Further work on the advancement of the system is expected to result in developing an algorithm controlling the speed of stretching the repaired structural elements of the vehicle bodywork, since the straightening of elements often results in their excessive and multiple deformations. The excessive and repeated deformations lead to unwanted weakening of the repaired elements and, consequently, of the whole structure. The algorithms controlling the straightening process should consider the characteristics of the material of the repaired elements. The straightening process will be performed automatically and will be fully controlled by feedback force (deformation force) until the factory shape of planes and the positions of reference points are restored.

Most connections in the bodywork structure are made using resistance spot welding. In the repairs, spot welding is often replaced by electric welding. Welding causes thermal deformation of elements and their decarburization. Therefore, also these phenomena need to be included in the straightening control algorithm.

The proposed idea requires many additional experimental studies and analyses. The measurements thus obtained need be confronted against the technical specifications of repaired vehicles - base point maps (provided by the manufacturer). The concept of the developed system is the starting point for construction and research works towards the full automation of works related to the repair of vehicle bodyworks. The proposed concept can significantly shorten the measurement and repair process and improve the quality of repairs performed in repair workshops. 


\section{Conclusion}

The considerations and examples of automation of bodywork measurement process presented allow to formulate the following conclusions:

- Measurement technology has recently evolved mainly due to the development of computer data processing technology.

- $\quad$ Contactless scanners play the predominant role in the vision measurement systems. They allow a relatively short time of data acquisition and relatively low cost of the process, they are used more and more increasingly, mainly in automated manufacturing processes.

- There are differences between the automation of measurement processes for construction and manufacturing purposes on the one hand, and the automation for repair processes on the other hand.

o In the process of constructing and formation of bodywork, non-contact scanning methods play a considerable role, and in particular the scanning method using scanners emitting structural light is becoming more and more popular.

o In diagnostics and repair processes, devices with contact-based measurement techniques are preferred.

- Measuring devices can be used in the vehicle diagnostics process. In the case of post-accident damage, they are usually used together with repair frames, because they allow tracking the repair process, giving current information on changes in the bodywork geometry. Analogue instruments, often integrated in measurement systems, are usually used for this purpose.

- The combination of experience in the field of automation of measurement processes practised in manufacturing processes with the automation of measurements of the bodywork geometry used for repair purposes gives a new quality in the technology of vehicle bodywork repairs. An expression of this synthesis is the proposed concept of including real-time measurement in the repair process.

- $\quad$ The proposed solution may be practically applied not only in repair processes, but also in periodic technical inspections of vehicles carried out at vehicle inspection stations. This will certainly increase the effectiveness of the inspection process and will contribute to the safety improvement on public roads.

Constantly increasing quality requirements of manufactured products, especially in the automotive industry, result in the need to use automated control systems characterized by very high accuracy and speed of measurement.

This applies to both manufacturing and diagnostic processes, including post-accident damage repair processes. Diagnostic and repair processes are also subject to increasingly rigorous legal restrictions to ensure greater safety of people using these vehicles in road traffic.

\section{Acknowledgement}

M.R.D., K.K.D., W.W. acknowledge the financial support from the program of the Polish Minister of Science and Higher Education under the name "Regional Initiative of Excellence" in 2019-2022, project no. 003/RID/2018/19, funding amount 11936 596.10 PLN and grants APVV-170258, 027TUKE-4/2020, VEGA 1/0290/18 and University Science Park TECHNICOM for Innovation Application Supported by Knowledge Technology-Phase 1, ITMS: 26220220182, supported by the Research and Development Operational Program funded by the ERDF and by the Slovak Research.

\section{References}

[1] BOZEK, P., POKORNY, P., SVETLIK, J.: The calculations of Jordan curves trajectory of the robot movement, International Journal of Advanced Robotic Systems, Vol. 13, No. 5, pp. 1-7, 2016.

[2] YODER, J.R., PAUL, R.: Opto-mechanical systems design, CRC press, 2005.

[3] CLEGG, CH.W.: Sociotechnical principles for system design, Applied ergonomics, Vol. 31, No. 5, pp. 463477, 2000.

[4] LECUN, Y., KAVUKCUOGLU, K., FARABET, C.: Convolutional networks and applications in vision, Proceedings of 2010 IEEE International Symposium on Circuits and Systems, pp. 253-256, 2010.

[5] KURADA, S., BRADLEY, C.: A review of machine vision sensors for tool condition monitoring, Computers in industry, Vol. 34, No. 1, pp. 55-72, 1997.

[6] WECKENMANN, A.: Multisensor data fusion in dimensional metrology, CIRP annals, Vol. 58, No. 2, pp. 701-721, 2009.

[7] BOŽEK, P., POKORNÝ, P.: Analysis and evaluation of differences dimensional products of production system, Applied Mechanics and Materials, Vol. 611, pp. 339-345, 2014.

[8] DUAN, Z.: High Precision Edge Detection Algorithm for Mechanical Parts, Measurement Science Review, Vol. 18, No. 2, pp. 65-71, 2018.

[9] JAYAS, D.S., PALIWAL, J., VISEN, N. S.: Review paper (AE-automation and emerging technologies): multi-layer neural networks for image analysis of agricultural products, Journal of Agricultural Engineering Research, Vol. 77, No. 2, pp. 119-128, 2000.

[10] LI, Y., GU, P.: Free-form surface inspection techniques state of the art review, Computer-Aided Design, Vol. 36, No. 13, pp. 1395-1417, 2004.

[11] HARŤANSKÝ, R., SMIEŠKO, V., RAFAJ, M.: Modifying and accelerating the method of moments calculation, Computing and Informatics, Vol. 36, No. 3, pp. 664-682, 2017.

[12] BERNARD, A., FISCHER, A.: New trends in rapid product development, CIRP Annals, Vol. 51, No. 2, pp. 635-652, 2002. 
[13] ASHDOWN, S.P., SUNG CHOI, M., MILKE, E.: Automated side-seam placement from 3D body scan data, International Journal of Clothing Science and Technology, Vol. 20, No. 4, pp. 199-213, 2008.

[14] VOYACHEK, I.I.: Quality management of fixed joints of parts, Machine builder, Vol. 5, pp. 17-18, 1997.

[15] BURANSKÝ, I., MOROVIČ, L., PETERKA, J.: Application of reverse engineering for redesigning and manufacturing of a printer spare part, Advanced Material Research, Vol. 690-693, pp. 2708-2712, 2013.

[16] FIXSON, S. K.: Product architecture assessment: a tool to link product, process, and supply chain design decisions, Journal of operations management, Vol. 23, No. 3-4, pp. 345-369, 2005.

[17] PORWAL, A., HEWAGE, K. N.: Building Information Modeling (BIM) partnering framework for public construction projects, Automation in construction, Vol. 31, pp. 204-214, 2013.

[18] KOWALSKI, M.: Automation of the threedimensional scanning process based on data obtained from the photogrammetric measurement, Advances in Science and Technology Research Journal, pp. 109119, 2011.

[19] KURIC, I., TLACH, V., SÁGOVÁ, Z., CÍSAR, M., GRITSUK, I.: Measurement of industrial robot pose repeatability, MATEC Web of Conferences, 2018.

[20] WILLIAMS, R.J.: Use of CAD/CAM technology to fabricate a removable partial denture framework, The Journal of prosthetic dentistry, Vol. 96, No. 2, pp. 96-99, 2006.

[21] ARAYICI, Y.: An approach for real world data modelling with the 3D terrestrial laser scanner for built environment, Automation in construction, Vol. 16, No. 6, pp. 816-829, 2007.

[22] PETERKA, J. POKORNÝ, P. VACLAV, S.: CAM strategies and surface accuracy, Annals of DAAAM and Proceedings of the International DAAAM Symposium: pp. 1061-1062, 2008.

[23] TREBUŇA, P., MIZERÁK, M., ROSOCHA, L.: 3D scaning-technology and reconstruction, Acta Simulatio, Vol. 4, No. 3, pp. 1-6, 2018.

[24] BRADLEY, C., CURRIE, B.: Advances in the field of reverse engineering, Computer-Aided Design and Applications, Vol. 2, No. 5, pp. 697-706, 2005.

[25] BARONE, S., PAOLI, A., RAZIONALE, A.V.: Shape measurement by a multi-view methodology based on the remote tracking of a 3D optical scanner, Optics and Lasers in Engineering, Vol. 50, No. 3, pp. 380-390, 2012.

[26] JIN, K.: Analysis and design for reducing residual stress and distortion after ejection of injection molded part with metal-insert, International journal of precision engineering and manufacturing, Vol. 15, No. 12, pp. 2533-2542, 2014.
[27] TILCH, S.: CLIPS-development of a novel camera and laser-based indoor positioning system, ETH Zurich, 2012.

[28] IVANOV, V., MITAL, D., KARPUS, V., DEHTIAROV, I., ZAJAC, J., PAVLENKO, I., HATALA, M.: Numerical simulation of the system "fixture-workpiece" for lever machining, The International Journal of Advanced Manufacturing Technology, Vol. 91, No. 1-4, pp. 79-90, 2017.

[29] BLANCO, M., VILLARROYA, I.: NIR spectroscopy: a rapid-response analytical tool, Trends in Analytical Chemistry, Vol. 21, No. 4, pp. 240-250, 2002.

[30] KLESZCZYNSKI, S.: Error detection in laser beam melting systems by high resolution imaging, In: Proceedings of the Solid Freeform Fabrication Symposium, 2012.

[31] LILLESAND, T., KIEFER, R. W., CHIPMAN, J.: Remote sensing and image interpretation, John Wiley \& Sons, 2015.

[32] KRUTH, J.P.: Computed tomography for dimensional metrology, CIRP annals, Vol. 60, No. 2, pp. 821-842, 2011.

[33] PETERKA, J., MOROVIČ, L., POKORNÝ, P., KOVÁČ, M., HORNÁK, F.: Optical 3D scanning of cutting tools, Applied Mechanics and Materials, Vol. 421, pp. 663-667, 2013.

[34] ISTOOK, C.L., HWANG, SU-J.: 3D body scanning systems with application to the apparel industry, Journal of Fashion Marketing and Management: An International Journal, Vol. 5, No. 2, pp. 120-132, 2001.

[35] LIVESEY, A., ROBINSON, A.: The repair of vehicle bodies, Routledge, 2006.

[36] SHI, H., WU, P.: Flexible vibration analysis for car body of high-speed EMU, Journal of Mechanical Science and Technology, Vol. 30, No. 1, pp. 55-66, 2016.

[37] PIVARČIOVÁ, E., SOBRINO, D.R.D., NIKITIN, Y.R., HOLUBEK, R., RUŽAROVSKÝ, R.: Measuring and evaluating the differences of compared images for a correct car silhouette categorization using integral transforms, Measurement Science Review, Vol. 18, No. 4, pp. 168-174, 2018.

[38] KURIC, I.: New methods and trends in product development and planning, International Conference on Quality and Innovation in Engineering and Management, Romania, pp. 453-456, 2011.

[39] HILLIER, V.A.W., COOMBES, P.: Hillier's fundamentals of motor vehicle technology, Nelson Thornes, 2004.

[40] GREENWALD, B.: Vehicle value appraisal system, U.S. Patent Application No 09/954,127, 2002.

[41] RATAJCZYK, E.: Results of coordinate measuring arms' accuracy testing, International Journal of Advanced Robotic Systems, Vol. 1, pp. 57-62, 2017. 
[42] LIONELLO, M.: Apparatus for acting of and reshaping the damaged bodywork of automobile vehicles, U.S. Patent No 3,776,022, 1973.

[43] BOŽEK, P., PIVARČIOVÁ, E.: Registration of Holographic Images Based on Integral Transformation, Computing and Informatics, Vol. 31, No. 6, pp. 1369-1383, 2012.

[44] RATAJCZYK, E.: The systems for geometrical measurements of car bodies, Archives of Mechanical Technology and Materials, Vol. 30, No. 2, pp. 107127, 2010.

[45] RATAJCZYK, E.: Systems for damaged car bodys measurements, Journal of KONES, Vol. 18, pp. 503508, 2011.

[46] MICHALOS, G.: Automotive assembly technologies review: challenges and outlook for a flexible and adaptive approach, CIRP Journal of Manufacturing Science and Technology, Vol. 2, No. 2, pp. 81-91, 2010.
[47] MAZURKIEWICZ, A.: Methodology of Technological Innovations Implementation Maturity Assessment, Journal of Machine Construction and Maintenance, Vol. 2010. pp. 5-20, 2010.

[48] GIESKO, T., BORONSKI, D.: Automated machine vision systems for fatigue studies, Journal of Machine Construction and Maintenance, Vol. 2003, pp. 177-188, 2003.

[49] VOYACHEK, I.I.: Rational Provision of Functional Properties of Interference Fit Joints in Case of Assembly with Implementation of Anaerobic Materials, Materials Science Forum, Trans Tech Publications, Vol. 2019, pp. 123-132, 2019.

\section{Review process}

Single-blind peer review process. 